\title{
Variação e possibilidades de uso do solo sobre rochas cristalinas na Amazônia oriental
}

Lourdes Ritter - Mestre em Agronomia pela Universidade Federal Rural da Amazônia, atualmente é bolsista PPBIO/CCTE/CNPQ.

Paulo Martins - Professor da Universidade Federal Rural da Amazônia/UFRA. Engenheiro Agrônomo, doutor em Solos e Nutrição de Plantas.

Miguel Cooper - Professor da Universidade de São Paulo-USP. Doutor em Agronomia (Solos e Nutrição de Plantas) pela Universidade de São Paulo-USP.

Catherine Grimaldi - Membro do Groupe NAJAC/Groupe de Recherches "Systèmes Pédologiques et Systèmes Agraires”, França.

\begin{abstract}
Resumo
A diversidade dos sistemas pedológicos é pouco considerada na Amazônia no contexto da pecuarização, em que a utilização do solo com pastagem tende a homogeneizar a paisagem. Isso se deve, em parte, ao desconhecimento dos potenciais usos dos diferentes tipos de solo e ao fato de a variação (vertical e lateral) do solo nas vertentes não ser muito bem percebida nem valorizada pelos agricultores. O objetivo principal deste estudo é conhecer as coberturas pedológicas predominantes em uma área do Projeto de Assentamento de agricultores familiares. Nesta pesquisa, utiliza-se uma abordagem baseada nas características morfológicas do solo. Os resultados demonstram que existe diversidade de solos ao longo de topossequências e sugerem usos diversos e mais adaptados às potencialidades e limitações desses solos.
\end{abstract}

\section{Palavras-chave}

Uso do solo. Cobertura pedológica. Frente pioneira. Amazônia.

\begin{abstract}
The diversity of pedological systems is rarely taken into account in agricultural activities like cattle ranching, where the use of ground for pasture tends to homogenize the landscape. This is attributed in part, to a lack of knowledge of the potential uses of different soil types, and the fact that the (vertical and lateral) variation of the soil sources are neither well understood or valued by local family farmers. The main objective of this study was to distinguish the main pedological covers in this region, identifying their principal characteristics in terms of structural organization and functioning in the landscape, taking different geomorphic structures into account via the Structural Analysis of Pedological Cover method. The results demonstrate that a diversity of soils types exist throughout the top sequences with a variety of uses depending on their specific potential and limitations.
\end{abstract}

\section{Keywords}

Soil use. Pedological cover. Pioneer frontier. Amazonia. 


\section{INTRODUÇÃO}

Quando se trata de sustentabilidade e resiliência (KAISER, 2004; LAL, 2004), na Amazônia em especial, o solo desempenha um papel dos mais destacados. Contudo, na maior parte das vezes, as atividades agrícolas não consideram as características e as potencialidades do solo (DOSSO et al., 2005). Embora existam diversos tipos de solos de fertilidade variável, como não há informações sobre sua localização no relevo, fica difícil planejar seus usos.

$\mathrm{Na}$ frente pioneira do sudeste do Estado do Pará, os agricultores familiares, via de regra, implantam pastos e ocupam indistintamente as diferentes posições do relevo. As variações do solo, determinadas pela geomorfologia das vertentes, percebidas pelos agricultores, são levadas em consideração nessa atividade apenas para determinar a espécie de gramínea a ser cultivada.

Esse processo de pecuarização é hoje em dia largamente denunciado como um obstáculo à durabilidade da agricultura e do meio ambiente. Ora, a diversificação das produções agrícolas poderia estabelecer os agricultores nos seus lotes e tornar a agricultura mais sustentável. Para atingir esse objetivo, é importante conhecer e considerar as potencialidades do solo adaptadas às diferentes produções.

O objetivo deste trabalho é mostrar que o relevo e a posição do solo na vertente são frequentemente determinantes da forte diversidade do solo numa mesma rocha-mãe. É possível reconhecer essa diversidade a partir de observações qualitativas do solo e orientar a planificação do uso do solo de acordo com a organização do relevo. Numa frente pioneira do sudeste do Estado do Pará, foi utilizado o método da análise estrutural da cobertura pedológica. Esse método foi usado inicialmente na Guiana Francesa (BOULET et al., 1982; BOULET; LUCAS; BRUNET, 1984; FRITSCH et al., 1986) e depois no Brasil. Por ele é possível identificar, no nível das superfícies geomórficas, os diferentes tipos de solos graças à análise de suas principais características e da geometria (arranjo) dos seus horizontes (RUELLAN; DOSSO, 1993). Ele parte do princípio de que o funcionamento da cobertura pedológica depende das características intrínsecas dos diversos horizontes e da sua organização ao longo de uma vertente.

\section{MATERIAL E MÉTODO}

\section{Caracterização da área de estudo}

A localidade de Benfica pertence ao município de Itupiranga e está situada na microrregião de Marabá (Figura 1) a 5 16' S de latitude e a 49 50’ W de longitude. O clima da microrregião de Marabá (Awi, segundo a classificação de Köppen) é do tipo tropical úmido, caracterizado por uma estação de chuvas e uma estação seca; 
apresenta precipitações anuais em torno de 1800 mm, com distribuição média da pluviosidade ao longo do ano que evidencia nitidamente uma estação de chuvas de aproximadamente sete meses, com máximo em março, e uma estação seca de cinco meses, com mínimo em julho. A estação seca, de maio a setembro, é um período de forte déficit hídrico (REYNAL et al., 1995): a pluviometria é quase sempre inferior à evapotranspiração potencial (ETP). A temperatura média diária varia fracamente no decorrer do ano, situando-se em torno de $26{ }^{\circ} \mathrm{C}$, com mínima de $23{ }^{\circ} \mathrm{C}$ e máxima de $36{ }^{\circ} \mathrm{C}$.

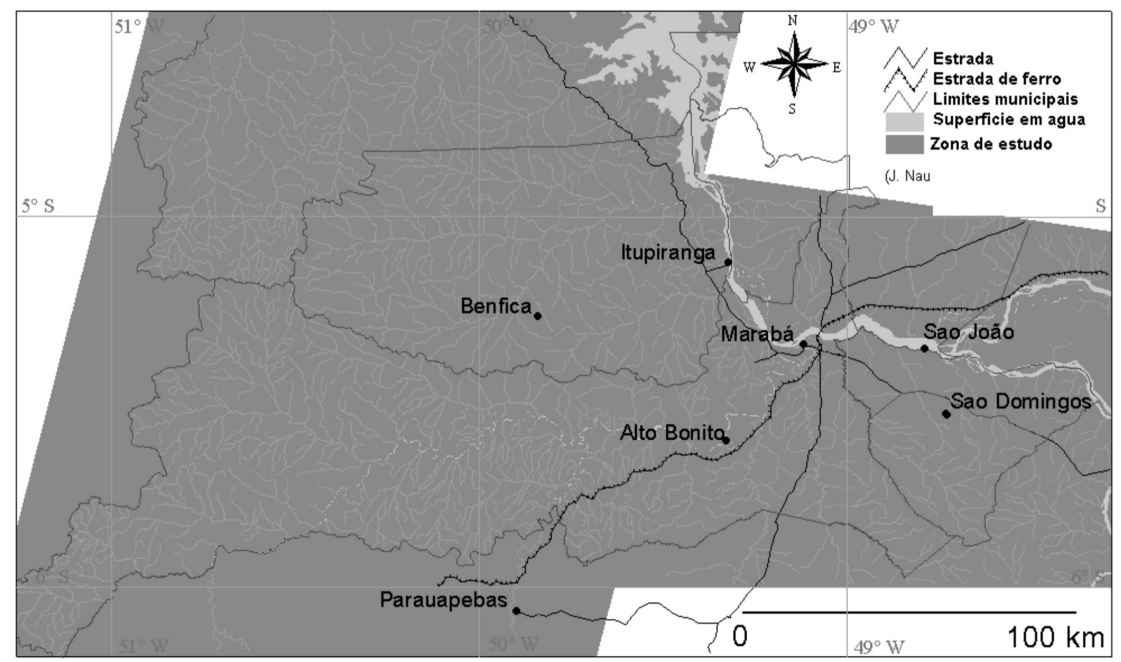

Figura 1: Localização da área de estudo (imagem cedida por J. Naudts (2003)).

A paisagem da localidade de Benfica é constituída de colinas alongadas, com vertentes de drenagem aberta (RUHE; WALKER, 1968), de extensão hectométrica a quilométrica e com menos de $50 \mathrm{~m}$ de desnível, desenvolvidas sobre dois tipos de rochas do escudo brasileiro (Paleoproterozóico). De forma preliminar, um foi classificado como biotita-hornblenda-granodiorita porfírica e o outro, como biotita-monzogranito de grão fino (DALL'AGNOL, 2004, informação verbal). O segundo tipo de rocha é predominante na área de estudo: tem cor escura e textura equigranular com grãos finos, é isótropo e constituído, principalmente, de quartzo, plagioclásio sódico, feldspato potássico (microclina) e biotita (mica negra ferromagnesiana); acessoriamente é constituído de alanita (epídoto) e de zircão. O primeiro tipo ocupa um espaço menor, principalmente na parte oeste da área: tem uma textura granular isótropa, com grãos médios e grosseiros, de cor acinzentada, o plagioclásio sendo composto provavelmente de andesina (mais 
rico em cálcio que na rocha anterior); os minerais preponderantes, associados ao quartzo, são fenocristais de feldspato alcalino potássico de tamanho milimétrico a centimétrico. Os principais minerais ferromagnesianos presentes são a hornblenda (anfibólio cálcico), verde, e a biotita, bruna (presença de titânio). Do ponto de vista geoquímico, o granodiorito deve ser relativamente mais rico em cálcio e mais pobre em potássio que o monzogranito.

Benfica possui 183 lotes agrícolas que ocupam uma superfície de $124 \mathrm{~km}^{2}$, com população estimada em mil habitantes. Dois conjuntos de agricultores foram distinguidos em função das suas histórias - época de ocupação e forma de aquisição do lote. O primeiro conjunto foi formado numa área de fazenda com pastagem degradada, a Fazenda Santa Isabel, ocupada a partir de 1994 por famílias sem terra e posteriormente designada como área para reforma agrária. Chamada "área dos colonos", ela contava em 2002 com 134 famílias explorando lotes (às vezes dois ou três por família) de 50 hectares aproximadamente. O segundo conjunto, chamado "área dos pequenos fazendeiros" estabeleceu-se numa fazenda vizinha à Fazenda Santa Isabel. Trata-se de uma área comprada principalmente por agricultores oriundos do Estado do Tocantins, dividida em 34 lotes de mais de 150 hectares cada. Essa divisão corresponde também a uma diferença de rocha originária do solo, respectivamente monzogranto para o primeiro conjunto e granodiorita para o segundo.

\section{MÉTODO}

A pesquisa foi iniciada com a identificação das principais superfícies geomórficas e dos principais tipos de ecossistemas da localidade. Isso foi feito por meio de sondagens nos lotes dos agricultores, observando-se a variação dos relevos, as características dos solos, os tipos de rochas e a vegetação presente. A diversidade dos solos foi avaliada inicialmente por meio de perfuração com o trado holandês e em cortes de estrada.

Depois da identificação das rochas, foram selecionadas três vertentes representativas das superfícies geomórficas da localidade, situadas sobre os dois substratos geológicos, sendo uma no monzogranito e duas no granodiorito, todas escolhidas sob pastagens de $B$. brizantha. As vertentes situadas sobre granodiorito constituem uma mesma colina, cuja forma é assimétrica. As três vertentes foram segmentadas com base em Ruhe e Walker (1968) e Ahnert (1970). As variações tanto verticais quanto laterais do solo dessas vertentes foram caracterizadas morfologicamente (cor, textura, consistência e umidade ao tato), até a profundidade de mais ou menos 3 metros, salvo nos casos de ocorrência de couraça laterítica ou camada arenosa no nível do lençol freático. O número de observações ao longo 
de cada toposseqüência dependeu da variação do solo: sempre que um horizonte não podia ser bem delimitado, foi realizadao uma sondagem suplementar, a meia distância entre as duas sondagens mais próximas (BOULET et al., 1982; LUCAS, 1983).

\section{RESULTADOS}

Sobre o granodiorito foram caracterizadas duas vertentes interligadas no topo e orientadas no sentido norte-sul (Figura 2). No lado norte (lado esquerdo da figura), fica a vertente maior, com declividade média de $6 \%$, e no lado sul está a vertente menor, com maior declividade, em torno de $12 \%$. A maior tem desde o topo uma forma convexa, com aproximadamente $12 \%$ de declive, depois um segmento côncavo com declividade em torno de 4,5\% e, enfim, um retilíneo não ultrapassando $3 \%$ de declive, o que permite classificá-la como de perfil complexo tipo convexo-côncavo-retilíneo (AHNERT, 1970). A vertente menor (lado sul) apresenta um segmento convexo, com aproximadamente $14 \%$ de declive no topo, procedido de um côncavo, com declividade de $21 \%$ no início até um sopé com $2 \%$ de declividade; constituindo um perfil composto do tipo convexo-côncavo (AHNERT, 1970).

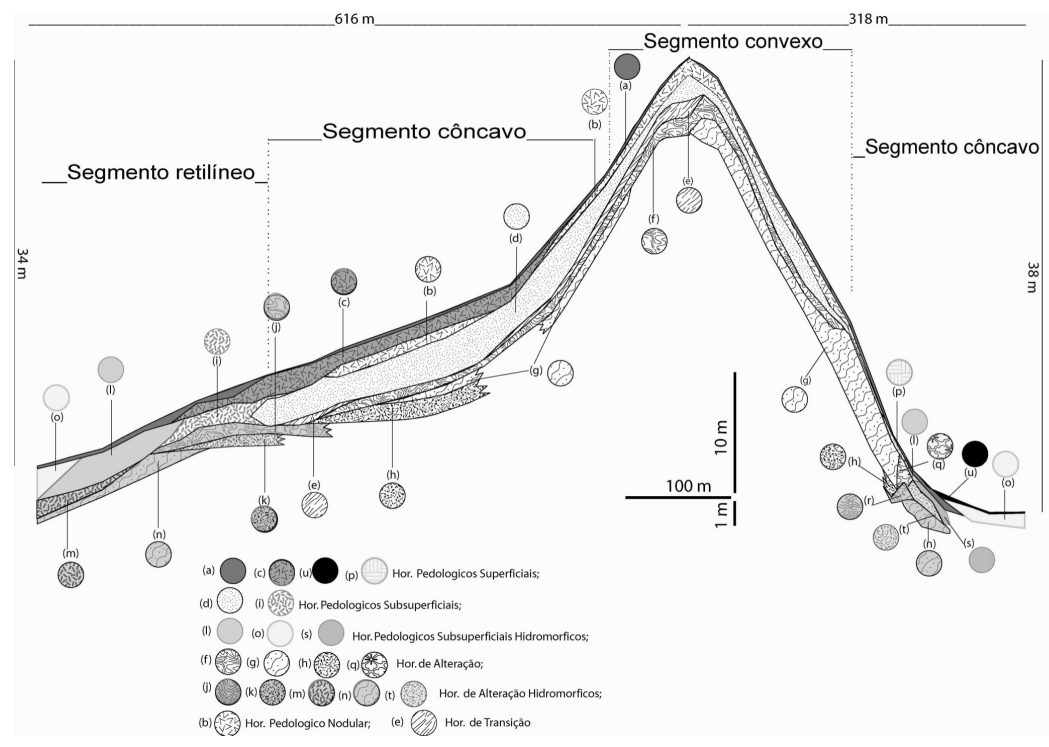

Figura 2: Organização da cobertura pedológica sobre o granodiorito.

Legenda:

(a) horizonte superficial de cor 10YR4/2 (bruno-acinzentado-escuro) a 10YR3/1 ou 2,5Y3/1 (cinza muito escuro), argiloarenoso (com a presença de areia grossa) a montante e franco-arenoso a areia franca à medida que se aproxima 
da jusante, friável, mais compacto que os horizontes subjacentes;

(b) horizonte de cor 10YR5/6 (bruno-amarelado), argiloso, rico em nódulos ferruginosos milimétricos a centimétricos a montante (cerca de 30\%), presença de grãos de quartzo solto ou nos nódulos, friável, pegajoso;

(c) horizonte de cor de 10YR4/4 (bruno-amarelado-escuro), argiloso a montante e argiloarenoso a jusante, friável, plástico e pegajoso;

(d) horizonte de cor 7,5YR5/8 (bruno forte) a 5YR5/8 (vermelho-amarelado), argiloso, com nódulos ferruginosos milimétricos a centimétricos duros e friáveis mais abundantes a montante, presença de grãos de quartzo centimétricos, muito friável, plástico e pegajoso na meia vertente;

(e) horizonte de transição de cor 7,5YR5/8 a 5YR5/8 (bruno forte a vermelhoamarelado), argiloso (com início de característica siltosa), poucos volumes brancos (caolinita), mosqueados amarelados e concreções vermelhas friáveis, consistência mais firme que a do horizonte (d), começando a ficar seco;

(f) horizonte de alteração de cor 5YR5/8 (vermelho-amarelado) com volumes brancos caoliníticos (cerca de 60\%), vermelhos-violáceos (com nódulos vermelhos-violáceos friáveis) e amarelos, argilossiltoso (índicos de sericita), firme, seco;

(g) horizonte de alteração de cor 2,5YR4/8 (vermelho), com volumes 2,5YR3/3 (amarelos, brancos e bruno-avermelhado escuro), argilossiltoso (indícios de sericita), firme, seco;

(h) horizonte de alteração com cor 7,5YR6/8 (amarelo-avermelhado) com volumes 2,5YR4/8 (vermelho), com mosqueados amarelos, brancos, amarelo-claros e vermelhos e nódulos ferruginosos friáveis, argilossiltoso (indícios de sericita), firme, seco;

(i) horizonte de cor 10YR5/4 a 10YR5/8 (bruno-amarelado) com poucos mosqueados escuros (10YR4/4) e avermelhados, argiloso, friável, plástico e pegajoso;

(j) horizonte de cor 10YR5/8 (bruno-amarelado) heterogêneo com volumes milimétricos bruno forte a vermelho-amarelado, vermelho e branco e nódulos friáveis e de bordas alteradas (com o centro muito duro), argiloso, úmido (influência do lençol freático na estação chuvosa), plástico;

(k) horizonte de cor 10YR6/4 (bruno-amarelo-claro) heterogêneo com volumes amarelos, vermelhos, cinzas e brancos, ausência de nódulos, presença do lençol freático na estação chuvosa, firme;

(l) horizonte de cor 2,5Y5/2 (bruno-acinzentado) a 2,5YR5/3 (bruno-oliva-claro), e mosqueados difusos 2,5Y5/4 (bruno-oliva-claro), arenoso a argiloarenoso, muito úmido (na estação chuvosa), plástico; 
(m) horizonte 2,5Y5/2 (bruno-acinzentado) a 2,5Y6/2 e 2,5Y6/4 (brunoacinzentado-claro), com mosqueados e volumes 5YR5/6 (vermelhoamarelado), 2,5YR4/8 (vermelho), 2,5YR6/2 (vermelho-claro), franco-arenoso a argiloarenoso, úmido, mais firme que (l);

(n) horizonte de cor 5B7/1 (cinza azul claro) com mosqueados e volumes 2,5YR4/8 (vermelho contrastante) e 5YR5/8 (vermelho amarelado), argiloarenoso, firme, seco;

(o) horizonte que varia de 10YR5/2 (bruno-acinzentado) a 10YR5/1 (cinzento) ou 10YR4/1 (cinza muito escuro) de montante a jusante, com mosqueados 10YR5/6 (bruno-amarelado), franco-arenoso (com areia grossa), com água livre na estação das chuvas;

(p) horizonte de cor heterogênea, variando entre 7,5YR5/6 a 7,5YR4/6 (bruno forte) a 10YR4/6 (bruno-amarelado-escuro) de montante a jusante, com mosqueados 2,5Y5/4 à 2,5Y6/4 (bruno-oliva-claro a bruno-amarelado-claro) e volumes 2,5YR4/8 (vermelho) centimétricos, franco-arenoso a argiloarenoso, friável, plástico, pegajoso;

(q) horizonte de cor heterogênea, 7,5YR5/8 (bruno forte) dominante, com volumes friáveis, 7,5YR7/6 (amarelo-avermelhado), (2,5Y7/4 (amarelo muito claro) ou 2,5Y6/3 (bruno-amarelado-claro), branco (quartzoso), franco-arenoso a argiloso, úmido a muito úmido na estação chuvosa, friável e plástico;

(r) horizonte 2,5Y6/3 (bruno-amarelado muito claro) a 2,5Y7/4 (amarelo muito claro), com volumes 2,5YR4/8 (vermelho) e 5YR5/8 (vermelho-amarelo), argiloso no conjunto (com volumes mais arenoso), consistência firme, presença de lençol freático na estação chuvosa (volumes mais secos no entanto);

(s) horizonte 10YR 5/3 (bruno) a 10YR6/2 (cinza-brunado-claro), com mosqueados pontuais $(7,5 \mathrm{YR} 5 / 8$, bruno forte), franco-arenoso, topo do lençol na estação chuvosa;

(t) horizonte de cor variegada, 2,5Y7/1 (cinza-claro) a 2,5Y7/3 (amarelo muito claro), com volumes 5YR5/8 (vermelho-amarelado), 7,5YR4/6 (bruno forte) ou 10YR4/4 (bruno-amarelado escuro), franco-argiloso a argiloso, plástico, úmido;

(u) horizonte superficial 10YR2/1 ou 2,5Y2,5/1 (negro), arenoso, água livre na estação chuvosa.

Sobre monzogranito, a vertente (Figura 3) apresenta na montante um segmento convexo, com um topo de baixa declividade, menor que $2 \%$, relativamente extenso em comparação aos encontrados sobre granodiorito, seguido por declividade que se aproxima de $12 \%$. Esse segmento é sucedido por um 
côncavo, com elevada declividade, em torno de $26 \%$, o que caracteriza, também, um perfil composto convexo-côncavo (AHNERT, 1970), de modo semelhante ao da vertente curta sobre granodiorita.

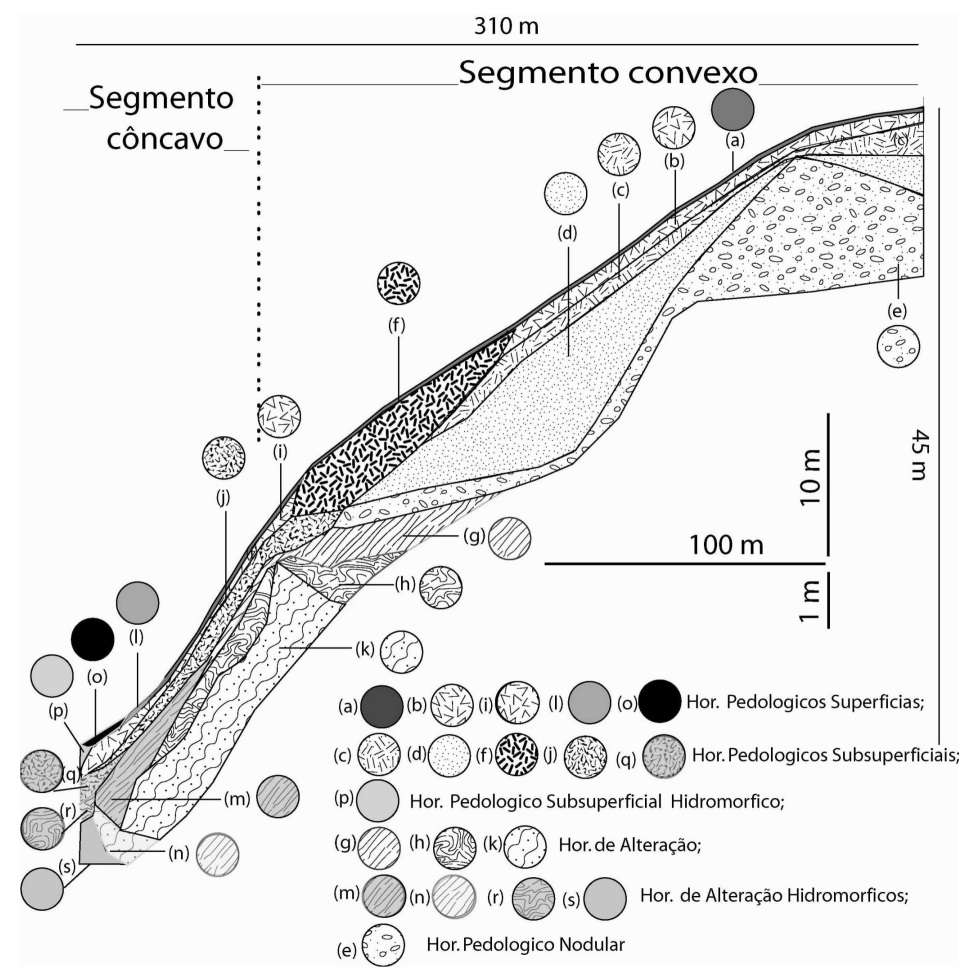

Figura 3: Organização da cobertura pedológica sobre monzogranito.

Legenda:

(a) horizonte superior de cor 10YR5/6 (bruno-amarelado), argiloso (a montante) a franco-argiloso (a jusante), mais compacto que o horizonte subjacente (b) ou (i);

(b) horizonte de cor 10YR5/6 (bruno-amarelado) com nódulos ferruginosos milimétricos, pretos e duros, argiloso, friável, plástico, pegajoso;

(c) horizonte de cor 7,5YR5/8 (bruno forte), com nódulos ferruginosos milimétricos, pretos e duros, muito argiloso, plástico, friável, pegajoso;

(d) horizonte de cor 7,5YR5/8 (bruno forte), com nódulos ferruginosos milimétricos e centimétricos (raros), pretos e duros, muito argiloso, friável, plástico, pegajoso;

(e) horizonte de cor 7,5YR5/8 (bruno forte), com muitos nódulos ferruginosos centimétricos vermelho-escuro (10R3/4) com o centro preto, argiloso;

(f) horizonte de cor 10YR5/8 (bruno-amarelado) com nódulos ferruginosos 
centimétricos duros (raros), argiloso, friável, plástico, pegajoso;

(g) horizonte de alteração de cor 5YR5/6 à 5YR5/8 (vermelho-amarelado), com nódulos vermelho-escuros, duros a quebráveis (na base do horizonte) com mosqueados amarelos, argiloso, mais compacto, consistência mais firme, menos pegajoso que (e), transição ao horizonte de alteração (h);

(h) horizonte de alteração de cor 5YR5/8 (vermelho-amarelado) com volumes vermelhos (2,5YR3/6) e mosqueados amarelos e brancos, argiloso a argilossiltoso (sericitoso), compacto, firme e seco;

(i) horizonte de cor 10YR5/8 (bruno-amarelado) com nódulos ferruginosos milimétricos e centimétricos pretos e duros, argiloarenoso, friável, plástico, pegajoso;

(j) horizonte de cor 7,5YR5/8 (bruno forte) com nódulos ferruginosos milimétricos e centimétricos duros e pretos (no topo) e vermelhos e quebráveis (na base), com mosqueados vermelhos e amarelos (da base em direção a jusante), argiloso, friável, plástico e pegajoso (no topo) a denso e firme (na base);

(k) horizonte de alteração de cor variegada, 7,5YR5/6 (bruno forte) ou 10YR6/8 (bruno-amarelado) e branco, argiloso a franco-argilossiltoso, mais ou menos denso e firme em função da textura, seco;

(l) horizonte superficial 10YR5/1 (cinza) a 2,5Y3/1 (cinza muito escuro) com mosqueados 7,5YR5/6 (bruno forte), argiloarenoso;

(m) horizonte de cor heterogênea, 10YR6/8 ou 6/6 (bruno-amarelado) com mosqueados 7,5YR5/8 (bruno forte), 2,5YR4/6 (vermelho), 5YR5/6 (vermelho-amarelado) e 10YR7/6 (amarelo), argiloso, consistência mais firme na base;

(n) horizonte bruno acinzentado muito escuro 10YR3/2 com variegados 10YR7/6 ou 2,5Y7/8 (amarelo) com volumes 5Y8/1 (branco), argiloso a argilossiltoso, consistência firme, úmido;

(o) horizonte superficial 10YR3/2 (bruno-acinzentado muito escuro), argiloarenoso;

(p) horizonte 2,5Y5/4 (bruno-oliva-claro) com volumes 5YR4/6 (vermelho e vermelho-amarelado), argiloso, úmido;

(q) horizonte 7,5YR4/6 (bruno forte) com volumes contendo mosqueados 10YR6/8 (amarelo) e 5YR4/6 (vermelho-amarelado) associados a poucos nódulos ferruginosos, argiloso, friável, plástico, pegajoso;

(r) horizonte 2,5Y 6/6 ou 6/8 (bruno-oliva) a 2,5Y6/4 (bruno-amarelado-claro) até a jusante, com volumes e mosqueados 2,5YR4/6 (vermelho) e gley1 8/1 (branco), poucos nódulos ferruginosos, argiloso, firme, pouco pegajoso, 
úmido;

(s) horizonte 10YR7/1 (cinza-claro) com volumes 2,5YR4/8 (vermelho), 5YR4/6 (vermelho-amarelado), 7,5YR5/6 (bruno forte) e 10YR5/6 (bruno-amarelado), argiloso a argilossiltoso, firme, úmido.

Sobre o granodiorito, na montante das vertentes, o horizonte superficial (Figura 2), ilustrado pela letra (a), apresenta-se rico em matéria orgânica, com textura argiloarenosa e cor bruno-acinzentado-escura ou cinza muito escuro e friável, mas há indícios de crostas superficiais nas áreas descobertas pela pastagem; progressivamente, à medida que a profundidade aumenta, o solo torna-se bruno-amarelado (b), com textura mais argilosa e contendo muitas concreções ferruginosas; entre 80 e $160 \mathrm{~cm}$ de profundidade, está o horizonte (d), de cor bruno forte a vermelho-amarelado, argiloso e mais friável e pegajoso do que o horizonte superior, ainda contendo nódulos ferruginosos, mas em quantidade cada vez menor à medida que se distancia da superfície. Esses horizontes superiores, mais ricos em matéria orgânica ou em argila e com estrutura bem desenvolvida, estão sobrepostos aos horizontes (e) de transição e (f) e (g) de alteração. As características específicas que diferenciam esses horizontes de alteração dos seus sobrejacentes e que permitem sua identificação são, principalmente, a presença de minerais primários (muscovita), a sua consistência mais firme e o caráter "seco ao tato", ou seja, não são úmidos nem pegajosos em quaisquer condições climáticas, em razão de uma estrutura pouco desenvolvida, de tendência maciça. A cor (nessa posição da vertente especificamente) é heterogênea, com variegados vermelhosvioláceos e brancos presentes num matiz vermelho-amarelado ( $\mathrm{f}$ ) ou vermelho (g); os nódulos milimétricos são esparsos e friáveis, de cor vermelho-violáceo e a textura é argilossiltosa, com indícios da presença de sericita.

Essa mesma distribuição dos horizontes, em geral, é verificada em parte do segmento côncavo da vertente maior, havendo algumas variações: o horizonte (b) cede lugar ao horizonte (c) bruno-amarelado escuro no início do segmento côncavo e vai-se alongando e espessando à medida que a concavidade da vertente aumenta até seu desaparecimento em bisel no segmento retilíneo a jusante; o horizonte (d) espessa-se progressivamente, atingindo quase $2 \mathrm{~m}$, desaparece em bisel no início do segmento retilíneo e cede lugar ao horizonte bruno-amarelado com mosqueados (i) e ainda mais a jusante ao (l) de cor heterogênea, mas dominada pela tonalidade cinza ou bruno-oliva típica da hidromorfia.

$\mathrm{Na}$ transição entre o segmento côncavo e o retilíneo, os horizontes de alteração (e), (f) e (g) também desaparecem em bisel, substituídos pelos horizontes (h), (j) e (k) de cores mais claras (amarelo-avermelhado, bruno-amarelado e bruno- 
amarelo-claro, respectivamente) e mais heterogêneas. Suas consistências são firmes; são horizontes $\mathrm{C}$ de alteração submetidos à influência do lençol freático, que se aproxima da superfície nessa posição.

No sopé da vertente, a sucessão vertical de horizontes de coloração acinzentada (o), (m) e (n) denota a permanência da água durante o período das chuvas. Foi observada também a grande espessura (cerca de $1 \mathrm{~m}$ ) do horizonte (o), de textura franco-arenosa com areia grossa e a consistência firme do horizonte de alteração (n).

A vertente menor apresenta na montante uma distribuição de horizontes idêntica à da vertente maior, contudo o horizonte (d) é menos espesso, e o horizonte (c) bruno-amarelado-escuro não aparece.

A partir do início do segmento côncavo, os horizontes de alteração (f) e (g) situam-se muito próximo da superfície, por sua vez, os horizontes estruturados do solo estão nessa posição, bem menos espessos do que são na montante e/ou na outra vertente.

O sopé dessa vertente, que de maneira diferente da vertente longa, forma curvatura característica do segmento côncavo, apresenta vários horizontes de alteração com heterogeneidade de cores e horizontes superiores de cores acinzentada a negra, próprias do efeito do hidromorfismo. A textura é progressivamente mais arenosa.

Sobre o monzogranito, na montante da vertente (Figura 2), os horizontes pedológicos variam de bruno-amarelo nos horizontes (a) e (b) a bruno forte a partir do (c); a textura muda de argilosa a muito argilosa entre eles; a compactação do solo é visível em superfície, devido ao pisoteio do gado; a consistência é friável, aumenta progressivamente de (b) para (d), corresponde à estrutura microagregada que se evidencia com a profundidade. Nódulos ferruginosos centimétricos são encontrados em abundância no horizonte (e) atingem $70 \%$ do volume na base. Esse horizonte nodular está presente desde o topo até a jusante do segmento convexo: depois de aproximar-se da superfície a montante, aprofunda-se progressivamente a mais de $3 \mathrm{~m}$ na parte central do segmento convexo, a partir de onde volta a aproximar-se da superfície, dessa vez fazendo limite na parte média da vertente com o horizonte de alteração (g), de cor vermelho-amarelada e consistência firme.

A variação do modelado desse horizonte nodular (e) é concomitante ao espessamento dos horizontes de cor bruno forte, sobretudo (d), os que desaparecem em bisel no final do segmento convexo quando o horizonte nodular aproxima-se da superfície.

Ao longo da vertente, os horizontes (b), (c) e (d) são substituídos pelo horizonte (f), bruno-amarelado, argiloso de consistência, mais firme na base do que em superfície. Na transição entre os segmentos convexo e côncavo, o horizonte 
(e) é substituído pelo (j), bruno forte, no qual a abundância em nódulos é inferior e eles se apresentam menos duros. À medida que a declividade do segmento côncavo aumenta, o horizonte (j) aproxima-se da superfície, chegando a menos de $30 \mathrm{~cm}$ de profundidade. Simultaneamente, os horizontes com presença de minerais primários e com consistência firme - características de horizontes de alteração (g), (h) (k), (m), (n) e (s) - aproximam-se da superfície. Os horizontes superficiais bruno-amarelado (a) de textura argilosa a montante e franco-argilosa a jusante e (i) de textura argiloarenosa são muito estreitos. A variação de cores entre os horizontes de alteração (h) e (k), ainda mais acentuada em (m) e (n), indica a influência do lençol freático e/ou do acúmulo de água nas posições mais baixas do relevo devido a condições desfavoráveis de drenagem. No final do segmento côncavo, correspondendo ao sopé da vertente, a presença de cores brunos-oliva ou acinzentadas, associadas a mosqueados abundantes, tanto nos horizontes da superfície (l) e (o), como em subsuperfície (p), (q), (r) e (s), indicam a forte ocorrência de hidromorfia.

\section{DISCUSSÃO}

\section{DIFERENCIAÇÃODOSOLONASVERTENTES:CARACTERÍSTICAS E PROCESSOS}

$\mathrm{Na}$ Amazônia, os processos que mais influem na formação e na evolução dos solos são os ligados à erosão, à redistribuição e à acumulação residual do ferro e do alumínio e à hidromorfia, favorecidos pelas condições de clima tropical úmido (BOULET et al., 1993; DUBROEUCQ; VOLKOFF, 1998; FRITSCH et al., 2005, 2006; LUCAS et al., 1996; NASCIMENTO et al., 2004). Esses processos estão presentes nas vertentes estudadas, como se verá a seguir. As organizações dos solos conhecidas a partir de tradagens ao longo de topossequências, com base nas características morfológicas de cor, textura, consistência e de extensão vertical e lateral dos horizontes, permitem as seguintes interpretações.

A primeira característica que diferencia os solos está relacionada à profundidade em que se encontra o topo dos horizontes de alteração da rocha nas topossequências. A montante na vertente sobre monzogranito, esse horizonte não foi atingido pela tradagem a $3 \mathrm{~m}$ de profundidade. De maneira contrastada, esses solos encontram-se perto da superfície a jusante da vertente. Nas vertentes sobre o granodiorito, a profundidade dos horizontes de alteração é também muito variável: menos de $0,5 \mathrm{~m}$ a jusante da vertente menor e mais do que $3 \mathrm{~m}$ no segmento côncavo da vertente maior. Por sua vez, a espessura dos horizontes A e $\mathrm{B}$ do solo depende dessa posição do horizonte $\mathrm{C}$ e da sua distância em relação à superfície. 
A proximidade dos horizontes de alteração em relação à superfície do solo ou a espessura dos horizontes $\mathrm{A}$ e $\mathrm{B}$ dependem do balanço entre os processos de erosão e de alteração. Os constituintes dos horizontes A e B são minerais residuais da alteração da rocha-mãe, primários (quartzo) ou secundários (caulinita e óxidos de ferro e alumínio) e matéria orgânica, submetidos a vários mecanismos de erosão. A erosão hídrica pode retirar partículas do solo e elementos diluídos na solução do solo. Na concavidade da vertente maior sobre granodiorita, as condições de declividade são desfavoráveis à erosão e há acumulação dos produtos do intemperismo. Nas partes mais elevadas do relevo, com declividade maior, a espessura menor dos horizontes A e B do solo indica erosão mais intensa. Possivelmente, os produtos erodidos estão acumulando-se na concavidade, quando a declividade diminui. A grande espessura do horizonte (c) bruno-amareladoescuro pode evidenciar esse acúmulo de argila e matéria orgânica. Pelo contrário, em condições de forte declividade, como se encontra na vertente menor sobre o granodiorito e na vertente sobre monzogranito, não existem condições de acúmulo dos produtos de intemperismo, ou seja, o componente erosivo na formação do solo parece predominante.

Os horizontes A e B têm consistência friável, característica de uma estrutura bem desenvolvida, devida em particular à atividade biológica (COOPER; VIDALTORRADO; CHAPLOT, 2005; ESCHENBRENNER, 1986). Desprovidos de minerais primários da rocha, exceto o quartzo, eles se diferenciam em função da abundância de nódulos ferruginosos, da quantidade de matéria orgânica e do regime hídrico, que se manifesta nas características morfológicas dos horizontes acessíveis a partir de tradagens. Os nódulos pretos ou vermelhos, duros ou quebráveis, estão em maior quantidade na cobertura pedológica sobre monzogranito, devido, provavelmente, à composição mineralógica e química dessa rocha. Ademais, sobre as duas rochas, mais abundantes nas partes mais elevadas dos relevos, constitui-se um horizonte nodular muito espesso sobre monzogranito. Sobre o granodiorito, esses nódulos encontram-se somente a montante das vertentes, em pequena quantidade, enquanto, sobre monzogranito, rocha frequentemente rica em biotita, os nódulos de tamanho centimétricos podem ocupar mais da metade do volume de solo.

A cor, às vezes mais escura do solo em superfície, resulta da incorporação da matéria orgânica, morfologicamente nítida, com 10 a $20 \mathrm{~cm}$ de profundidade (horizonte organomineral A). Nos sopés das três vertentes, observa-se um horizonte A bem mais desenvolvido, resultante de dois mecanismos complementares: uma transferência de matéria orgânica de montante a jusante e uma mineralização desfavorecida nas condições mais úmidas. 
Os horizontes subsuperficiais argilosos e friáveis têm uma cor bruno forte indicadora, nesse caso, de boas condições de drenagem da água. Esse fato depende da estrutura bem desenvolvida do horizonte, ou seja, da característica intrínseca do solo. Além disso, a drenagem da água é determinada por características extrínsecas: posição do volume de solo considerado na topossequência em relação ao relevo (montante/jusante, declividade) e dentro da cobertura pedológica (presença de um horizonte subjacente com baixa condutividade hidráulica que limita o fluxo de água). Sobre o monzogranito, a variação de cor em profundidade, desde o topo até o final do segmento convexo, pode estar ligada a variações decorrentes da estrutura, que influencia diretamente a drenagem; a cor mais intensa (bruno forte) dos horizontes (c) e (d) indica não haver condições de hidromorfia nesses horizontes. O desaparecimento em bisel dos horizontes bruno forte (c) e sobretudo (d) no final do segmento convexo, substituídos por um horizonte bruno-amarelado de mais de $1 \mathrm{~m}$ de espessura, pode refletir diminuição na drenagem da água, uma vez que o horizonte de alteração menos permeável aproxima-se da superfície; porém, pode ser associado também a uma microagregação do solo menos desenvolvida, que favorece a retenção da água por um período mais prolongado (FRITSCH et al., 2005). As cores mais acinzentadas, que indicam condições hidromórficas, estão presentes nos horizontes superficiais do solo, não somente a jusante das vertentes, como também a montante, quando o solo está compactado pelo pisoteio do gado. A jusante das três vertentes, a hidromorfia manifesta-se em todo o perfil pedológico.

Por fim, a hidromorfia é outro processo de diferenciação do solo que se manifesta com maior intensidade a jusante das três vertentes estudadas. A presença do lençol freático que se aproxima da superfície na estação chuvosa é a origem das condições prolongadas de saturação em água, que transformam todos os horizontes do solo, inclusive os de alteração. As cores acinzentadas são indicadoras da redução do ferro, a qual precede a sua mobilidade e sua exportação do solo para o sistema de drenagem. Além disso, a textura do solo torna-se mais arenosa à medida que a hidromorfia manifesta-se com maior intensidade porque, nesse caso, o desaparecimento dos óxidos de ferro precede a dissolução da caulinita (FRITSCH, 1984). Foi observado, também, ao longo das vertentes, o desenvolvimento da hidromorfia na superfície do solo, devido à compactação causada pelo pisoteio do gado (GRIMALDI et al., 1993).

Em função da intensidade desses processos, distinguem-se três tipos de solo: (i) latossolo, com um horizonte B espesso e rico em nódulos ferruginosos, (ii) cambissolo, com horizonte $\mathrm{B}$ incipiente e horizonte $\mathrm{C}$ muito próximo da superfície, e (iii) gleissolo, com horizonte A enriquecido em matéria orgânica e horizontes A 
e B empobrecidos em argila, e manifestação da hidromorfia em todo o perfil.

Esses tipos de solos muito contrastados, porém ligados um ao outro, constituem na paisagem dois tipos de sistema pedológico: um sistema latossolocambissolo-gleissolo, observado sobre os dois tipos de rocha de Benfica (Figuras 4 e 5) e um sistema latossolo-gleissolo, somente sobre o granodiorito (Figura 5). O primeiro sistema foi repetidamente descrito, por exemplo, na Guiana Francesa em condições geológicas e climáticas comparáveis (BOULET, 1978; BOULET et al., 1979, 1993; SABATIER et al., 1997), interpretado como uma cobertura latossólica em desequilíbrio nas condições atuais (GRIMALDI et al., 2004). O segundo sistema parece mais original, pela ausência de cambissolo na parte média do relevo e, ao contrário, pelo grau de desenvolvimento do latossolo associado à declividade menor. A hidromorfia devolve-se, então, mais a jusante, a partir do latossolo.
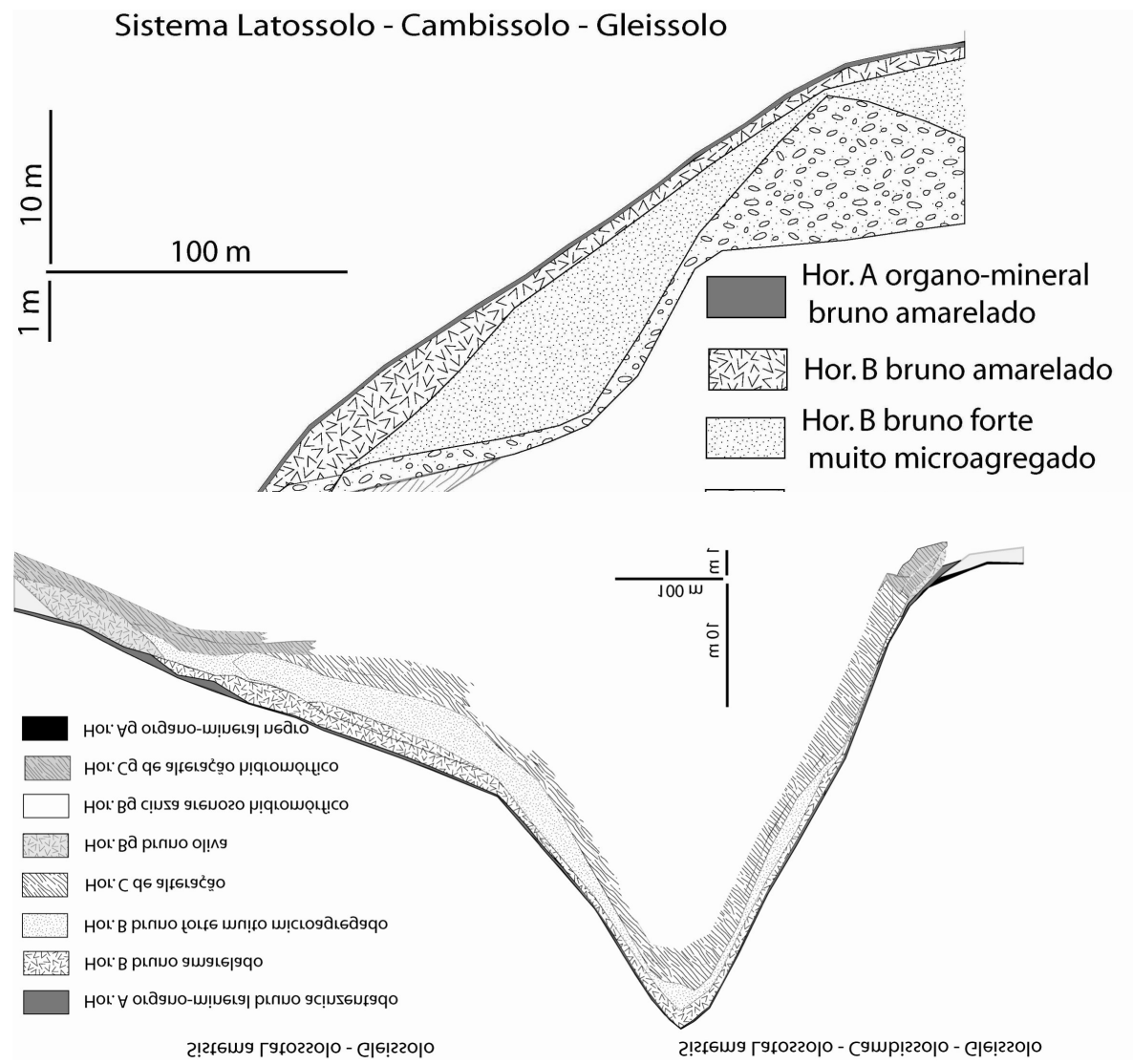

Figura 5: Sistema pedológico sobre granodiorita.

\section{IMPLICAÇÕES QUANTO AO USO DO SOLO}


No Projeto de Assentamento (PA) Benfica, e de uma maneira geral na frente pioneira da Amazônia oriental, o ritmo de implantação das pastagens é hoje mais rápido do que há vinte ou mesmo dez anos. O arroz é a cultura anual mais frequente que precede ou acompanha a plantação de gramíneas forrageiras. Para os agricultores que dispõem de pouco capital, essa gestão é geralmente a que valoriza melhor o trabalho familiar e a terra disponível (BRAND; SICARD, 2003). Apesar das medidas governamentais incentivando os agricultores a permanecer em seus lotes, a preservar a cobertura florestal e a diversificar suas produções, foi observada uma dinâmica rápida de transformação da floresta em pastagens, seguida de concentração fundiária. Isso acontece mesmo que as condições do meio físico sejam favoráveis à diversificação.

Existem na Amazônia solos de fertilidade elevada, devido à constituição mineralógica ou orgânica e, consequentemente, à composição química, em particular as terras pretas (KERN, 1996; KERN; COSTA, 1997), os nitossolos (terra roxa estruturada) e os solos de várzeas. Entretanto, a maioria das terras cultiváveis não apresenta características químicas tão favoráveis; com argilominerais do tipo caulinita, os solos têm baixa capacidade de troca de cátions (CTC), dependendo mais da matéria orgânica. Aliadas à quantidade e à qualidade da matéria orgânica, as propriedades físicas do solo, sobretudo aquelas que influenciam o regime hídrico do solo, determinam a fertilidade potencial desses solos.

Com base em descrições morfológicas simples do solo ao longo de vertentes, verificou-se que a distribuição dos solos na paisagem não é feita ao acaso; está ligada às superfícies geomórficas facilmente identificáveis. Assim, é possível basear-se na morfologia da paisagem para sugerir o uso do solo mais adaptado às potencialidades e às limitações. Numa localidade de agricultura familiar, como a do PA Benfica, existe uma diversidade de solos que geralmente não é imediatamente percebida pelos agricultores, nem levada em consideração na gestão dos lotes.

O regime hídrico do solo em particular pode ser avaliado de maneira qualitativa a partir da descrição das características morfológicas do solo. Assim, a variação ao longo das vertentes implica diferenças na drenagem e no armazenamento da água que podem acentuar-se de acordo com a declividade, com possibilidade de efeitos diferenciados sobre o desenvolvimento das raízes das plantas. Essas variações traduzem-se em parte na diferença de cores encontradas tanto nos horizontes de uma mesma vertente como nas três vertentes estudadas, o que suscita possibilidades diferenciadas de uso do solo.

Os latossolos argilosos de profundidade média predominam nessa localidade. São encontrados nos segmentos convexos a montante de cada uma das três vertentes estudadas, e a espessura determina a importância do volume de solo 
facilmente explorável pelas raízes e o regime hídrico do solo, pois a condutividade hidráulica diminui fortemente no nível dos horizontes de alteração (GUEHL, 1984; HUMBEL, 1978). Esses solos oferecem boas condições de drenagem da água, ou seja, nunca há excesso de água na estação chuvosa, como evidencia a cor homogênea bruno vivo do horizonte B. Se a estrutura bem desenvolvida desse horizonte, com microagregação, estabelece a macroporosidade entre os microagregados, o que favorece a drenagem da água, por outro lado a retenção da água pode ser INSUFICIENTE para suprir as necessidades das plantas em períodos longos de estiagem, principalmente nas posições mais elevadas do relevo. Ainda mais que a água útil às plantas é somente armazenada na microporosidade, ou seja, em condições em que as plantas não exercem sucções suficientes para aproveitar a água retida nos poros dentro dos microagregados. Os latossolos de profundidade média são, então, mais adaptados ao cultivo de lavouras anuais de ciclo curto, pelo risco de escassez de água no período de estiagem (HODNETT et al., 1995). Foi verificado no PA Benfica que a pastagem de Brachiaria brizantha manifesta um estresse hídrico nessa posição da vertente. Uma limitação desses solos é a tendência à compactação em alguns anos de uso (SARTRE et al., 2005) devido ao efeito do pisoteio do gado e à redução da atividade biológica no solo em relação à floresta. Os agricultores percebem esse fato, falando do "endurecimento do solo de barro amarelo". Provavelmente o teor elevado em argila, agravado pelo caráter de agregados pouco estáveis desses solos, favoreça a compactação. A presença dos nódulos, mesmo que abundantes, não deve ser considerada como impedimento ao desenvolvimento das raízes, exceto tubérculos, como consideram outros autores (REYNAL et al., 1995).

Os latossolos argilosos muito profundos - encontrados no segmento côncavo da vertente longa sobre o granodiorito e no final do segmento convexo sobre o monzogranito, com maior capacidade de estocagem de água, devido à espessura dos horizontes com estrutura microagregada e à posição topográfica - destacam-se como os mais aptos às culturas anuais e perenes, ou mesmo às pastagens de maior produtividade.

Nos segmentos menos elevados e de forte declividade das vertentes, tanto sobre o monzogranito como naquela de curta extensão sobre o granodiorito, os horizontes de alteração pouco permeáveis à água, perto da superfície, causam, depois das chuvas, saturação mais ou menos duradoura do solo, que drena lateralmente, aumentando o risco de erosão e a falta de água no período de estiagem. Essa situação é adversa ao desenvolvimento da maioria das plantas cultivadas, parecendo ser mais conveniente, nesse caso, preservar a vegetação natural.

Os solos do sopé das vertentes são hidromórficos, portanto de uso sob 
condições especiais, que pode ser tanto com pastagens, a partir de gramíneas adaptadas, como já ocorre na localidade de Benfica, quanto com vegetação natural, se for açaizal, por exemplo. Se não, considerando a fertilidade química desses solos, devido à abundância de matéria orgânica, cultivos de ciclo curto podem aproveitar a presença de água sem excesso na estação seca. Outra possibilidade, utilizando-se práticas específicas, como a construção de leiras, consiste em permitir os cultivos de ciclo mais longo, como o da mandioca.

Comparando-se o potencial de uso das três vertentes, pode-se dizer que, de modo geral, a mais longa (sobre granodiorita) reúne melhores condições que as demais porque possui menor declividade, solos mais profundos e em maior extensão. Contudo, ainda há necessidade de análises para detalhar os aspectos referentes à disponibilidade de água para melhor avaliar os aspectos ligados à disponibilidade de nutrientes.

\section{REFERÊNCIAS}

AHNERT, F. An approach towards a descriptive classification of slopes. Zeitschrift für Geomorphologie, v. 9, p. 71-84, 1970.

BOULET, R. Existence de systèmes à forte différenciation latérale en milieu ferrallitique guyanais: un nouvel exemple de couvertures pédologiques en déséquilibre. Science du Sol -Bulletin de l'AFES, n. 2, p. 75-82, 1978.

BOULET, R.; CHAUVEL, A.; HUMBEL, F. X.; LUCAS, Y. Analyse structurale et cartographie en pédologie: I. Prise en compte de l'organisation bidimensionnelle de la couverture pédologique: les études de toposéquences et leurs principaux apports à la connaissance des sols. II. Une méthode d'analyse prenant en compte l'organisation tridimensionnelle des couvertures pédologiques. III. Passage de la phase analytique à une cartographie générale synthétique. Cahiers ORSTOM, série Pédologie, v. 19, n. 4, p. 341-351, 1982.

BOULET, R.; FRITSCH, E.; HUMBEL, F-X. Les sols des terres hautes et de la plaine côtière ancienne en Guyane française septentrionale: organisation en systèmes et dynamique actuelle de l'eau. Cayenne: ORSTOM, 1979. 170 p.

BOULET, R.; LUCAS, Y; BRUNET, D. Importance de la différenciation pédologique latérale dans l'expérimentation agronomique en Guyane française. In: INSTITUT NATIONAL DE LA RECHERCHE AGRONOMIQUE. Prairies guyanaises et élevage bovin. Paris, 1984. p. 103-126 (Les Colloques de l'INRA, 24). Actes de la réunion interinstituts INRA, ORSTOM, GERDAT, CayenneSuzini, 15-16 déc. 1981. 
BOULET, R.; LUCAS, Y.; FRITSCH, E.; PAQUET, H. Géochimie des paysages: le rôle des couvertures pédologiques. In: PAQUET, H.; CLAUER, N. (Ed.). Sédimentologie et géochimie de la surface: colloque à la mémoire de Georges Millot. Paris: Académie des Sciences, 1993. p. 55-76.

COOPER, M.; VIDAL-TORRADO, P.; CHAPLOT, V. Origin of microaggregates in soils with ferralic horizons. Scientia Agricola, Piracicaba, v. 62, n. 3, p. 256-263, 2005.

DOSSO, M.; ASSIS, W. S. de; MEDINA, C. de C.; CURMI, P.; GRIMALDI, C.; GRIMALDI, M.; GUIMARÃES, M. de F.; JOUVE, P.; MARTINS, P. F.; NAVEGANTES, L.; OLIVEIRA, M.; RALISCH, R.; RUELLAN, A.; SILVA, L. M. S.; SIMÕES, A. V.; TAVARES FILHO, J.; VEIGA, I. Agriculture ou élevage? Rôle des couvertures pédologiques dans la différenciation et la transformation de systèmes agraires pionniers au Brésil. Cahiers Agricultures, v. 14, n. 1, p. 76-84, jan./fev. 2005.

DUBROEUCQ, D.; VOLKOFF, B. From Oxisols to Spodosols and Histosols: evolution of the soil mantles in the Rio Negro basin (Amazonia). Catena, v. 32, n. 3, p. 245-280, jun. 1998.

EMBRAPA. Sistema brasileiro de classificação de solos. 2. ed. Rio de Janeiro, 2006. 412 p.

ESCHENBRENNER, V. Contribution des termites à la micro-agrégation des sols tropicaux. Cahiers ORSTOM, série Pédologie, v. 22, n. 4, p. 397-408, 1986.

FRITSCH, E. Les transformations d'une couverture ferrallitique: analyse minéralogique et structurale d'une toposéquence sur schistes en Guyane française. 1984. 190 p. Thèse $3^{\text {e }}$ cycle - Université Paris VI, ORSTOM, Paris, 1984.

FRITSCH, E.; BOCQUIER, G.; BOULET, R.; HUMBEL, F.-X. Les systèmes transformants d'une couverture ferrallitique de Guyane française: analyse structurale d'une formation supergène et mode de représentation. Cahiers ORSTOM, série Pédologie, v. 22, n. 4, p. 361-395, 1986.

FRITSCH, E.; HERBILLON, A. J.; DO NASCIMENTO, N. R.; GRIMALDI, M.; MELFI, A. J. From Plinthic Acrisols to Plinthosols and Gleysols: iron and groundwater dynamics in the tertiary sediments of the upper Amazon basin. European Journal of Soil Science, v. 58, n. 5, p. 989-1006, 2007.

FRITSCH, E.; MORIN, G.; BEDICI, A.; BONNIN, D.; BALAN, E.; CAQUINEAU, S.; CALAS, G. Transformation of haematite and Al-poor goethite 
to Al-rich goethite and associated yellowing in a ferralitic clay soil profile of the middle Amazon Basin (Manaus, Brazil). European Journal of Soil Science, v. 56, n. 5, p. 575-588, 2005.

GRIMALDI, C.; GRIMALDI, M.; MILLET, A.; BARIAC, T.; BOULEGUE, $\mathrm{J}$. Behaviour of chemical solutes during a storm in a rainforested headwater catchment. Hydrological processes, v. 18, n. 1, p. 93-106, 2004.

GRIMALDI, M.; SARRAZIN, M.; CHAUVEL, A.; LUIZÃO, F.; NUNES, N.; RODRIGUEZ, M. de R.; AMBLARD, P.; TESSIER, D. Effets de la déforestation et des cultures sur la structure des sols argileux d'Amazonie brésilienne. Cahiers Agricultures, v. 2, n. 1, p. 36-47, 1993.

GUEHL, J. M. Dynamique de l'eau dans le sol en forêt tropicale humide guyanaise. Influence de la couverture pédologique. Annales des Sciences Forestières, v. 41, n. 2, p. 195-236, 1984.

HODNETT, M. G.; PIMENTEL DA SILVA, L.; ROCHA, H. R. da; CRUZ SENNA, R. Seasonal soil water storage changes beneath central Amazonian rainforest and pasture. Journal of Hydrology,v. 170, n. 1-4, p. 233-254, 1995.

HUMBEL, F. X. Caractérisation par des méthodes physiques, hydriques et d'enracinement de sols de Guyane française à dynamique de l'eau superficielle. Sciences du Sol, n. 2, p. 83-93, 1978.

KAISER, J. Wounding earth's fragile skin. Science, v. 304, n. 5677, p. 1616-1618, jun. 2004.

KERN, D. C. Geoquímica e pedogeoquímica em sítios arqueológicos com terra preta na Floresta Nacional de Caxiuanã (Portel-PA). 1996. 119 p. Tese (Doutorado em Geologia e Geoquímica) - Universidade Federal do Pará, Belém, 1996.

KERN, D. C.; COSTA, M. L. Os solos antrópicos. In: LISBOA, P. L. B. (Org.). Caxiuanã. Belém: Museu Paraense Emílio Goeldi, 1997. p. 105-119.

LAL, R. Soil carbon sequestration impacts on global climate change and food security. Science, v. 304, n. 5677, p. 1623-1627, jun. 2004.

LUCAS, Y. Méthode d'etude des couvertures pédologiques dans l'opération ECEREX. Cahiers ORSTOM, série Pédologie, v. 19, n. 4, p. 8-22, 1983. 
LUCAS, Y.; NAHON, D.; CORNU, S.; EYROLLE, F. Genèse et fonctionnement des sols en milieu équatorial. Comptes Rendus de l'Académie des Sciences. Série II. Science de la Terre, v. 322, n. 1, p. 1-16, 1996.

MARTINS, P. F. S. Análise crítica sobre a pesquisa agronômica aplicada na Amazônia. Novos Cadernos NAEA, Belém, n. 29, p. 123-138, 1993.

NASCIMENTO, N. R. do; BUENO, G. T.; FRITSCH, E.; HERBILLON, A. J.; ALLARD, TH.; MELFI, A. J.; ASTOLFO, R.; BOUCHER, H.; LI, Y. Podzolization as a deferralitization process: a study of an Acrisol-Podzol sequence derived from Palaeozoic sandstones in the northern upper Amazon Basin. European Journal of Soil Science, v. 55, n. 3, p. 523-538, set. 2004.

REYNAL, V. de; MUChAGATA, M. G.; TOPALl, O.; HÉBETTE, J. Agriculturas familiares e desenvolvimento em frente pioneira Amazônica. Clamecy: Nouvelle Imprimerie Laballery, 1995. 69 p.

REYNAL, V. de; MUCHAGATA, M. G.; TOPALL, O.; HEBETTE, J. Des paysans en Amazonie: agriculture familiale de développement du front pionnier amazonien. In: THERY, H. (Ed. Sci.). Environnement et développement en Amazonie brésilienne. Paris: Belin, 1997. cap. 4, p. 76-123.

RUELLAN, A.; DOSSO, M. Regards sur le sol. Paris: Foucher, 1993. 192 p.

RUHE, R. V.; WALKER, P. H. Hillslope models in soil formation. I Open system. In: THE TRANSACTIONS OF THE $9^{\text {TH }}$ INTERNATIONAL CONGRESS OF SOIL SCIENCE. Adelaide, 1968, v. 4. p. 551-560.

SABATIER, D.; GRIMALDI, M.; PREVOST, M.-F.; GUILLAUME, J.; GODRON, M. DOSSO, M.; CURMI, P. The influence of soil cover organization on the floristic and structural heterogeneity of a Guianan rain forest. Plant Ecology, v. 131, n. 1, p. 81-108, 1997.

SARTRE, X. A. de; ALBALADEJO, C.; MARTINS, P.; VEIGA, I.; GRIMALDI, M. Identification et évaluation de la diversité des modes d'exploitation des milieux en Amazonie orientale. Cahiers Agricultures, v. 14, n. 1, p. 85-89, jan./fev. 2005. 